\title{
The Effect of Barium Content on the Crystallization and Microhardness of Barium Fluormica Glass-Ceramics
}

\author{
Maher Rashwan ${ }^{1,2^{*}}$, Michael J. Cattell ${ }^{1}$, Robert G. Hill ${ }^{1}$
}

\begin{abstract}
${ }^{1}$ Centre for Oral Bioengineering, Barts and the London, School of Medicine and Dentistry, Queen Mary University of London, Mile End Road, E1 4NS, UK. ${ }^{2}$ Department of Conservative Dentistry, Faculty of Dentistry, Alexandria University, Alexandria, Egypt.
\end{abstract}

*corresponding author;

Email:m.r.a.mohamed@qmul.ac.uk

Tel: +44 2078825974 


\section{ABSTRACT}

Mica glass-ceramics are easily machined due to their "House-of-Cards" microstructure. Barium fluormica glass-ceramics were developed and indicated good mechanical properties. This work studies the effect of varying barium content on the crystallization and microhardness of mica glassceramics. Four glasses were produced with different baria contents, then converted to mica glassceramics using a two-step heat treatment. They were characterized using Differential Scanning Calorimetry [DSC], X-ray Diffraction [XRD], Scanning electron microscopy [SEM] and Vickers microhardness. DSC showed some formulations indicated bulk crystallisation as the dominant mechanism. XRD showed the crystallization of Barium fluorphlogopite in all the compositions with minor secondary phases. SEM showed the formation of "House-of-Cards" microstructures and with an increase in $\mathrm{BaO}$ content, a decrease in contrast was observed in back scattered mode. Exceptionally low hardness values $(<2 \mathrm{GPa})$ were obtained for longer heat treatments/holding times and are related to the well-developed house-of-cards microstructures formed.

Key Words: Glass; Glass-Ceramic; Fluormica; Microstructure. 


\section{Introduction}

Glass-ceramics are polycrystalline materials containing a residual glass with a dispersed crystalline phase. They are synthesized by controlled crystallisation of glass, where this controlled process results in the formation of partially crystalline, crack free material, which can be used for various biomedical applications [1, 2]. In 1970's tetrasilicic fluormica-containing glass-ceramics were developed by Beall and Grossman [3-6] and since then fluormica glass-ceramics have attracted the interest of many researchers due to their unique machinability. A material is considered machinable if it can be readily milled, drilled or turned using standard metal-working (primarily carbide) tools [7]. Fluormica glass-ceramics are a good example as they can be easily machined to the desired form using conventional tipped tools [3, 8-9]. The machinability of fluormica glassceramics are a direct result of their unique 'house-of-cards microstructure', made up of randomly oriented plate-like fluormica crystals that impinge on one another, embedded in the glassy matrix. This microstructure prevents fracture by offering preferential cleavage along the 001 plane of the mica crystal during the machining process $[7,10]$.

Dicor $^{\circledR}$ and Dicor MGC ${ }^{\circledR}$ [Corning Inc., Corning N.Y] were the first fluormica glass-ceramics produced for dentistry, with a stoichiometry based on a tetrasilicic potassium fluormica [11]. Dicor $\mathrm{MGC}^{\circledR}$ showed excellent machinability. However, its poor flexural strength [152 MPa] [12] and low fracture toughness values [1.0-1.40 MPa.m $\left.{ }^{0.5}\right]$ [13] limits its use in dentistry.

Uno et.al. 1991 studied the substitution of the monovalent potassium interlayer cations in potassium fluorphlogopite mica crystals by divalent barium cations [14]. This substitution increases the cleavage stress of the mica crystal and increases both flexural strength $[350 \mathrm{MPa}]$ and fracture toughness $\left[2.3 \mathrm{MPa}^{0.5}\right]$ of the produced glass-ceramics. This increase in strength and fracture toughness makes barium fluorphlogopite mica glass-ceramics potentially attractive for applications in dentistry.

Barium-based fluorphlogopite glass-ceramics are good candidates to be used with dental CAD/CAM technologies to produce inlays, onlays and crowns. Previous studies have investigated alumina content, fluorine content and magnesium content [15-21]. This study investigates the influence of increasing barium content in barium-based fluormica systems and its effect on nucleation, crystallisation, microstructure and microhardness. This makes it an interesting area to investigate, for better control over both physical and mechanical properties of this category of glasses and glass-ceramics. 
The glass compositional design used in this work $\left[8 \mathrm{SiO}_{2}-1.25 \mathrm{Al} \square \mathrm{O}_{3}-3.75 \mathrm{MgO}-2.25 \mathrm{MgF}_{2}-[\mathrm{X}] \mathrm{BaO}\right]$ is based on the general formula of fluormica stated by Pauling et al. (1930) [22], which allows the substitution of different components in order to study its effect on different properties and behavior of mica glasses and glass-ceramics. Excess silica $(8 \mathrm{~mol})$ was used to assist glass formation, while using ( $>2$ mol) magnesium fluoride was to ensure crystallization of fluorphlogopite. The aluminum to fluorine ratio was designed to be at least $1: 1$, in order to prevent volatilization of fluorine as stated in fluorine retention guidelines [17] [23].

\section{MATERIALS AND METHODS}

\subsection{Glass synthesis}

Four barium based fluormica glasses were produced using glass forming formula: $8 \mathrm{SiO}_{2}$ $1.25 \mathrm{Al}_{2} \mathrm{O}_{3}-3.75-\mathrm{MgO}-2.25 \mathrm{MgF}_{2}-[\mathrm{X}] \mathrm{BaO}$

Where $\mathrm{X}=1$ (Mica I); 1.3 (Mica II); 1.6 (Mica III) and 1.9 (Mica IV). In this compositional design the aluminium to fluorine and silicon to aluminium ratio were kept constant.

Glass forming reagents for each composition were weighed and heated in a platinum crucible in a furnace [EHF 17/3 Lenton, Hope Valley, UK), at $1500{ }^{\circ} \mathrm{C}$ for $1.5 \mathrm{~h}$. The molten glass batch was stirred inside the crucible for 10 seconds and then quenched into deionized water and the frit collected with a $500 \mu \mathrm{m}$ sieve [Endecotts Ltd., London, UK)]. The glass frit was then dried in an electric oven at $80{ }^{\circ} \mathrm{C}$ for 24 hours. $100 \mathrm{~g}$ of the glass frit was ground using a Gy-Ro mill (Glen Creston, London, UK) for 7 minutes. The ground glass was then sieved through a $45 \mu \mathrm{m}$ stainless steel sieve [Endocotts Ltd., London, England] to produce glass powder. The glass frits were also re-melted in a platinum crucible for $15 \mathrm{mins}$ at $1500{ }^{\circ} \mathrm{C}$ and then cast into pre-heated $\left[550{ }^{\circ} \mathrm{C}\right.$ for 30 mins] graphite moulds [Morgan Matroc, Stourport, England] to produce cylindrical glass rods (diameter $=14 \mathrm{~mm}$ and length $=100 \mathrm{~mm}$ ). 


\subsection{Differential scanning calorimetry (DSC)}

Glass frit and $<45 \mu \mathrm{m}$ powder samples $(50 \mathrm{mg}$ ) were used for DSC experiments. Specimens were heated from $23{ }^{\circ} \mathrm{C}$ to $1000^{\circ} \mathrm{C}$ at a rate of $20^{\circ} \mathrm{C} / \mathrm{min}$ in a flowing $(60 \mathrm{ml} / \mathrm{min})$ nitrogen atmosphere, in a DSC1500 [Rheometric Scientific, Epsom, UK].

\subsection{Simultaneous Thermal Analysis [STA]}

A simultaneous thermal analyser [STA1500, Thorn Scientific, UK] was used to determine weight loss and potential volatilization of fluorine from the glasses. Weighed glass frit and powder samples $(<45 \mu \mathrm{m})$ were placed into platinum crucibles and run in a temperature range of $100^{\circ} \mathrm{C}$ $1200{ }^{\circ} \mathrm{C}$, against analytical alumina powder at a heating rate of $20^{\circ} \mathrm{C} / \mathrm{min}$ (in presence of Nitrogen gas). Computer software used to analyse both DSC and TGA traces, to determine different glass transitions and weight loss during heat treatments.

\subsection{Glass-ceramics synthesis}

Cast glass rods produced in section 2.1 for each glass composition were placed into a high temperature furnace [UAF 17/12, Hope Valley, Lenton, U.K] at room temperature and heated at a rate of $20^{\circ} \mathrm{C} / \mathrm{min}$. Glasses were heat treated using a two-step heat treatment protocol by holding for 1 hour at $660{ }^{\circ} \mathrm{C}$ followed by crystal growth hold at $1150{ }^{\circ} \mathrm{C}$ or $1200{ }^{\circ} \mathrm{C}$ for 1,3 and 5 hours respectively (Table 2). After heat treatment the glass-ceramics were left inside the furnace to cool overnight. Glasses were heat treated to $1150{ }^{\circ} \mathrm{C}$ and $1200{ }^{\circ} \mathrm{C}$, as previous studies showed that the amount of barium fluormica phases increases with increasing heat treatment temperature up to $1200^{\circ} \mathrm{C}[17,18]$.

\subsection{X-ray Diffraction [XRD]}

XRD analysis was carried out for the starting glasses and glass-ceramic powder samples (size $<45 \mu \mathrm{m}$ ) using Panalytical X'PERT PRO X-ray diffractometer [Panalytical, The Netherland] using. A Bragg-Brentano flat plate geometry and $\mathrm{Cu} \mathrm{K \alpha}$ radiation $(\lambda 1=1.54059 \AA$ and $\lambda 2=1.54442 \AA)$. Powder samples were packed into stainless steel holders. Patterns were collected from 5 to $70^{\circ} 2 \theta$ 
with an interval of $0.0334^{\circ}$ and a step time of $200 \mathrm{sec}$. XRD data were analyzed using X'Pert Data Collector (v2.2, Panalytical, Almelo, The Netherlands). The JCPDS files used to identify crystalline phases were Barium fluorophlogopite (00-019-0117), Barium Aluminium Silicate (01088-1048) and Protoenstatite, synthetic (04-007-8621).

\subsection{Vickers Microhardness test}

Microhardness analysis was obtained on the glasses and glass-ceramics samples embedded in epoxy resin. Samples were lapped using silicon carbide grinding paper $(220,320,500,800$ and 1200 grit-size) and polished using $1 \mu \mathrm{m}$ alumina oxide polishing media (Buehler, USA) on a lapping machine (Struers, Knuth Rotor, Glasgow, UK).

A Vickers hardness tester [ZHV30-S, Zwick/Roell AG, Germany] was used with an attached high sensitivity camera [902B WATEC, Japan]. Samples were indented using a pyramid diamond indenter with an angle of $136^{\circ}$, under an applied load of $300 \mathrm{~N}$. The test force was maintained for 10 seconds, then diagonal lengths of the indentation were measured and used to calculate the Vickers hardness $(\mathrm{Hv})$, using the following equation:

$$
H v=\frac{2 P \sin (\theta / 2)}{d^{2}}
$$

Where: $H v$ is Vickers hardness; $\mathrm{P}$ is applied load $(\mathrm{N}) ; \theta$ is the angle of the pyramid and $\mathrm{d}$ is mean diagonal of indentation (mm). For each sample, Vickers microhardness values of 12 points were recorded and converted to GPa by multiplying by 9.806 [standard gravity] and divided by 1000 .

\subsection{Statistical analysis of the data}

Microhardness data were analyzed using a one-way ANOVA (Holm-Sidak method, Sigma Plot version 12.5, Systat Software Inc.), to compare significant differences between test groups $(\mathrm{P}<$ $0.05)$. 


\subsection{Scanning electron microscopy [SEM]}

Glass-ceramic samples from each heat treatment series were embedded in resin [Epofix, Struers A/S, Ballerup, Denmark] and left to set overnight. Samples were ground using silicon carbide papers $(320,500,800,1200$ and 4000 grit-size) and polished to an optical finish with $1 \mu \mathrm{m}$ alumina oxide polishing media (Buehler, USA) on a lapping machine [Struers, Knuth Rotor, Glasgow, UK], then cleaned in an ultrasonic bath [Kerry Ultrasonics, North Yorkshire, UK] for 10 minutes.

Samples were gold coated using a sputter Coater [Emitech SC 7620, Quorum Technologies, and UK.] for 60 seconds. Specimens were viewed in a scanning electron microscopy [FEI Inspect F, Hillsboro, Oregon, USA], in both the back scattered and secondary electron imaging modes.

\section{Results and Discussion}

DSC results (Fig. 1, Table 1) of the formed glasses showed that glass transition temperatures glasses were in the range $626-632{ }^{\circ} \mathrm{C}$. It also showed the appearance of a second crystallisation peak with an increase in the barium content of the glass for compositions II, III and IV (Figs. 1 b, c, d).

The DSC traces for Mica I (Fig. 1a, Table 1) agreed well with what had been considered during compositional design and stated in a previous study by Henry and Hill (2004) [15]. This study indicated reducing alumina content to 1.25 moles reduces the glass transition temperature. Henry and $\mathrm{Hill}$ found a $\mathrm{Tg}$ of $654{ }^{\circ} \mathrm{C}$ for a higher $\mathrm{Al}_{2} \mathrm{O}_{3}(1.5 \mathrm{~mol})$ content whilst glass transition temperatures for the present glasses were in the range $626-632{ }^{\circ} \mathrm{C}$. The reduction in alumina content leads to a shift in the role of some alkali earth cations needed to charge balance $\mathrm{AlO}_{4}{ }^{-}$ tetrahedra. Excess cations may lead to the formation of non-bridging oxygen atoms, reducing glass network connectivity and glass transition temperatures. The appearance of a second crystallisation peak with increasing the barium content of the glass for compositions II, III and IV (Figs. 1 b, c, d) indicates a switch in the crystallisation mechanism may be evident, although other minor phases are also present. This second crystallisation peak could be due to formation phases other than Barium fluorphlogopite $\left(\mathrm{Ba} 0.5 \mathrm{Mg}_{3} \mathrm{Si}_{3} \mathrm{AlO}_{10} \mathrm{~F}_{2}\right)$ more rich in barium, such as Kinoshitalite $\left(\mathrm{BaMg}_{3} \mathrm{Si}_{2} \mathrm{Al}_{2} \mathrm{O}_{10}(\mathrm{OH} / \mathrm{F})_{2}\right)$ which has a very similar crystal structure to that of Barium fluorphlogopite. Neutron diffraction studies are needed to confirm such assumption see ref [24]. 
Moreover, the two mica phases probably have different susceptibilities to surface nucleation and that's why it appears more with the frit rather than the powdered samples.

XRD results of these heat treated glass compositions (Figs. 2 a-d), indicated the formation of an additional barium-rich crystal phases and protoenstatite. Crystallisation of some glass compositions appear to occur by bulk crystallisation (Figs 1b, d). This finding is based on the fact that almost no change in crystallisation temperatures occurred on increasing the glass particle size from powder $(<45 \mu \mathrm{m})$ to frit $(1-2 \mathrm{~mm})$ for Mica II and IV compositions (Table 1). The bulk crystallisation mechanism for fluormica glasses has been reported by several studies previously $[6,15,25]$.

STA results (Table 1) revealed that the amount of weight loss which occurred to the glass during heat treatment is related to the particle size or surface area of the sample. Decreasing surface area of the heat treated glass by using frit particles instead of powder particles $(<45 \mu \mathrm{m})$ resulted in reduction of the percentage weight loss.

XRD results of the glasses and mica glass-ceramics (I, II, III and IV) are shown in Figs 2a-d. All glasses were shown to be amorphous, while analysis of the Mica glass-ceramics XRD patterns revealed formation of a major crystal phase of Barium fluorphlogopite $\left(\mathrm{Ba} 0.5 \mathrm{Mg}_{3} \mathrm{Si}_{3} \mathrm{AlO}_{10} \mathrm{~F}_{2}\right)$ with its diffraction peaks at $8.8^{\circ}, 17.8^{\circ}, 33.8^{\circ}, 38.5^{\circ}, 45.7^{\circ}$ and $60^{\circ}$. It should be mentioned here that these peaks also match those of Kinoshitalite $\left(\mathrm{BaMg}_{3} \mathrm{Si}_{2} \mathrm{Al}_{2} \mathrm{O}_{10}(\mathrm{OH})_{2}\right)$. However, a study by Hill et al. (2004) on similar compositions found that this crystal phase is a barium fluorphlogopite based on MAS-NMR [26]. XRD patterns in the current study also detected the formation of possible minor fluorine deficient crystal phases of barium aluminium silicate, with one peak at $22.4^{\circ}$, and Protoenstatite with peaks at $28.1^{\circ}, 30.7^{\circ}$ and $35^{\circ}$. Barium aluminium silicate is alumina and silicate rich phase formed usually in barium-containing fluormica glass-ceramics, especially when barium content is above the fluorophlogopite stoichiometry, while Protoenstatie are rich in silicon, magnesium. Both secondary phases were probably associated with loss of fluorine from the glass surface. The formation of barium aluminium silicate and Protoenstatite has been correlated to increased heat treatment temperatures [15]. This correlation was not surprising as the formation of Protoenstatite has been previously linked before with melting of the main barium fluorphlogopite phases at high temperatures $[15,26]$. A peak $\left(22.4^{\circ}\right)$ for a possible barium aluminium silicate phase in the Mica I glass-ceramic appeared to show an increase in peak intensity 
with increasing heat treatment temperature and time $\left(1200^{\circ} \mathrm{C}\right.$ for 5 hours). Formation of such fluorine deficient secondary phases above $>1100^{\circ} \mathrm{C}$ have been previously reported by Beall (1985) and Henry and Hill (2004) [15, 27,28]. The formation of a small amount of secondary fluorine deficient phases is however not thought to affect the machinability of the produced glass-ceramics [29]. Some of those fluorine deficient phases could be clearly seen in SEM photomicrographs showing the surface layer of the produced glass-ceramics (Fig. 6).

SEM photomicrographs of the Mica I glass-ceramic composition (Figs. 3a, b, 5) showed the formation of a house-of-cards microstructure with increased temperature and holding time as reported in previous studies $[10,15,19]$. An Oswald ripening process was thought to be responsible for driving the crystal coarsening mechanism [30-33]. This microstructure of elongated barium fluormica crystals that interconnect has been determined as the pre-requisite for obtaining machinability in Mica glass-ceramics [10]. It provides a preferential path for cleavage during machining, along the 001 plane [interlayer sites] of the mica crystals. This preferential cleavage (path) can be clearly seen in (Figs. 3 c, d).

Back scattered SEM photomicrographs (Fig. 4 a, b , c and d) revealed that with increasing $\mathrm{BaO}$ content in glass the composition the contrast in back scattered mode starts to decrease. Extra $\mathrm{BaO}$ above the mica stoichiometry would be expected to remain in the residual glass phase. In Mica IV the back scattered contrast has reversed (Fig.4d). The glass phase now back scatters more strongly than the barium mica crystal phase and this probably reflects higher barium content in the residual glass phase.

SEM photomicrographs (Fig. 4 a, b, c and d) also showed that the volume fraction of barium mica crystal phases appears to be high. However it was difficult to quantify this due to decrease of contrast in the back scattered mode with increasing barium content (Fig.4d). Moreover, the microcracking and splitting of mica crystals in the softer glass-ceramics after polishing made it impossible to measure the apparently high volume fraction of mica crystals accurately (Fig.5). This is supported by the very low microhardness values observed. Accurate determination of volume fraction and crystallite size was also difficult because of the reduced back scattered contrast between the mica phase and the residual glass phase as the $\mathrm{BaO}$ content was increased.

There were also signs of some minor spherical domains (more obvious in Figs. 4c, d), which could be linked to the minor XRD phases identified or earlier nucleation events. 
Back scattered SEM photomicrographs also indicated the formation of surface layers containing phases other than barium fluormica (Fig.6). This layer may be fluorine deficient and was detected in all heat treatments. The crystal phase at the surface back scatters more strongly than the barium mica phase seen in the interior and may be richer in barium. It is thought to be the barium aluminosilicate phase seen previously in the XRD. It is formed due to volatilization of fluorine in the form of $\mathrm{SiF}_{4}$ as reported before $[15,21]$. The thickness of this fluorine deficient layer was only about $30 \mu \mathrm{m}$ (Fig.6), in contrast to other commercial mica-based glass-ceramics where the fluorine deficient surface layer is often much thicker [15].

Before crystallisation heat treatments there was no statistical difference $(\mathrm{P}>0.05)$ in the Mean microhardness between Mica glass test groups, except between Mica I (1 mol \% BaO) and Mica IV (1.9 mol \% $\mathrm{BaO})$, where excess $\mathrm{BaO}$ appears to have influenced the glass network and significantly reduced the microhardness (Table 2). The glass-ceramic microhardness values in the current study can be related to the development of the house-of-cards microstructure of the mica glass-ceramic. Increased crystal aspect ratio and coarsening of the mica crystals and the resultant residual glass appear related to a significant reduction in the microhardness within the formulation groups tested. This was clearly evident at increased heat treatment temperature and holding times (Fig. 3 b, Table 2). Significant reductions in Mean microhardness were found at 1, 3 and 5 hours $\left(1200{ }^{\circ} \mathrm{C}\right)$ for each test group $(\mathrm{p}<0.05)$. Increased crystal volume fraction and crystal length to width ratios were in evidence for the Mica I, II, III and IV glass-ceramics $\left(1200^{\circ} \mathrm{C} / 5\right.$ hours hold), which are properties suggested for optimised machining [34]. The low hardness values of mica glass-ceramics have also been reported to be another determinant for the machinability of the material $[35,36]$. Microhardness values $<2.0 \mathrm{GPa}$ were found for some of the current compositions at higher heat treatment temperatures $\left(1200^{\circ} \mathrm{C}\right)$ and are in a lower range $(1.3-1.8 \mathrm{GPa})$ than previously reported in the literature. The lowest hardness value reported for the commercial mica glass-ceramic $\mathrm{MACOR}^{\circledR}$ is about $2.1 \mathrm{GPa}$ [37]. The current formulations when heat treated at higher temperatures/longer holding times $\left(1200{ }^{\circ} \mathrm{C}\right.$ for 5 hours $)$ are probably too soft for dental ceramic restoration applications, as their hardness values are much lower than human enamel (3.1$3.7 \mathrm{GPa}$ ) [38] so might encounter rapid wear. For engineering applications the rough surfaces formed on machining could also be a drawback. The compositions that exhibit hardness values 
close to enamel at about 3.5 GPa may offer a good compromise between machinability and hardness, which would make them could good candidates for CAD/CAM dental restorations.

\section{Conclusions}

Novel barium fluormica glasses and glass-ceramics were successfully synthesised with increasing barium contents (1-1.9 mol.). All four compositions formed interlocking mica crystals and a house of card microstructure in which barium fluorphlogopite was the major crystal phase formed. Increasing barium content above mica stoichiometry decreases the contrast in back scattered mode as the more barium remains in the residual glass. Microhardness values of glasses showed a significant decrease $(\mathrm{P}<0.05)$ with increasing barium content, while microhardness values of glass-ceramics showed a significant decrease $(\mathrm{P}<0.005)$ with increasing heat treatment holding time and temperature. Exceptionally low hardness values (1.3-1.8 GPa) were obtained for longer heat treatments/holding times $\left(1200^{\circ} \mathrm{C} / 5 \mathrm{~h}\right)$ and are related to the well-developed house-of-cards microstructures formed obtained. 


\section{Acknowledgements}

The authors would like to acknowledge Dr. Sherif Elsharkawy for his valuable assistance in SEM studies.

\section{References}

[1] W. Höland, G.H. Beall, Glass-Ceramic Technology, Second ed., John Wiley \& Sons, New Jersey, 2012, pp.75-206. doi:10.1002/9781118265987.

[2] A. E. McHale, Engineering properties of glass-ceramics: ASM Int Eng Mater Handbook, 4 (1991) 870-878.

[3] G. Beall, L. Hench, Advances in Nucleation and Crystallization in Glasses, in: L.L. Hench, S.W. Freiman (Eds.), Am. Ceram. Soc., Westerville, OH, 1971, pp.251-261.

[4] G.H. Beall, Mica glass-ceramics, US Patent, 3689293, Corning Glass Works, Corning, N.Y., 1972.

[5] D.G. Grossman, Fluor-amphibole glass-ceramics, US Patent, 3839056, Corning Glass Works, Corning, N.Y. 1974.

[6] Chyung K, Beall G, D.G. Grossman, Fluorphlogopite mica glass-ceramics. Tenth Int Congr Glas. (1974) 33-40.

[7] W. Vogel, W. Höland, The Development of Bioglass Ceramics for Medical Applications, Angew. Chemie Int. Ed. English. 26 (1987) 527-544. doi:10.1002/anie.198705271.

[8] C.K. Chyung, G.H. Beall, D.G. Grossman, Microstructure and mechanical properties of mica glass-ceramics, in: G. Thomas (Ed.), The Fifth International Materials Symposium The Structure and Properties of Materials-Techniques and Applications of Electron Microscopy, University of California, Berkeley, 1971, pp. 1167-1194.

[9] X. Chen, D. Lu, S. Zhai, L. Teng, M. Zhang, X. Zhang. Research on the mechanism of phase separation, nucleation and crystallization of fluorophlogopite and fluorapatite containing glass-ceramics, Adv Mater. 93 (1994) 37-42. doi: 10.1016/B978-1-4832-83807.50017-1

[10] D.G. Grossman, Machinable Glass-Ceramics Based on Tetrasilicic Mica, J. Am. Ceram. Soc. 55 (1972) 446-449. doi:10.1111/j.1151-2916.1972.tb11337.x. 
[11] R.W.K. Li, T.W. Chow, J.P. Matinlinna, Ceramic dental biomaterials and CAD/CAM technology: state of the art, J. Prosthodont. Res. 58 (4) (2014) 208-216.

[12] J. Thompson, S. Bayne, H. Heymann, Mechanical properties of a new mica-based machinable glass ceramic for CAD/CAM restorations, J Prosthet Dent. 76 (1996) 619-623. doi:10.1016/s0022-3913(96)90440-0.

[13] R. Seghi, I. Denry, S. Rosenstiel, Relative fracture toughness and hardness of new dental ceramics, J Prosthet Dent. 74 (1995) 145-150. doi:10.1016/s0022-3913(05)80177-5.

[14] T. Uno, T. Kasuga, K. Nakajima, High-Strength Mica-Containing Glass-Ceramics, J. Am. Ceram. Soc. 74 (1991) 3139-3141. doi:10.1111/j.1151-2916.1991.tb04314.x.

[15] J. Henry, R. Hill, Influence of alumina content on the nucleation crystallization and microstructure of barium fluorphlogopite glass-ceramics based on $8 \mathrm{SiO}_{2} \cdot \mathrm{YAl}_{2} \mathrm{O}_{3} 4 \mathrm{MgO}_{2} \mathrm{MgF}_{2} \mathrm{BaO}$ Part I Nucleation and crystallization behaviour, J Mater Sci. 39 (2004) 2499-2507. doi:10.1023/b:jmsc.0000020016.18068.e6.

[16] A. Mallik, P. Kundu, A. Basumajumdar, Nucleation, crystallization behavior and microstructure of mica glass-ceramics in the system $\mathrm{SrO} \cdot 4 \mathrm{MgO} \cdot \mathrm{x} \mathrm{Al}_{2} \mathrm{O}_{3} \cdot 6 \mathrm{SiO}_{2} \cdot 2 \mathrm{MgF} 2$ ( $x=1,1.5$ and 2), Ceramics International. 39 (2013) 6963-6969. doi:10.1016/j.ceramint.2013.02.033.

[17] E. De Barra, R. Hill, Influence of glass composition on the properties of glass polyalkenoate cements. Part III: influence of fluorite content, Biomaterials. 21 (2000) 563569. doi:10.1016/s0142-9612(99)00215-x.

[18] A.R. Molla, B. Basu, Microstructure, mechanical, and in vitro properties of mica glassceramics with varying fluorine content, J. Mater. Sci. Mater. Med. 20 (2009) 869-882. doi:10.1007/s10856-008-3643-7.

[19] P.K. Maiti, A. Mallik, A. Basumajumdar, P. Kundu, Influence of fluorine content on the crystallization and microstructure of barium fluorphlogopite glass-ceramics, Ceram. Int. 36 (1) (2010) 115-120.

[20] S. Wu, Q. Zhou, Y. Wang, M. Zhang, Y. Chen, Effect of fluorine content on the crystallization and flexural strength of fluoro-mica glass ceramics, Ceramics International. 39 (2013) 4187-4190. doi:10.1016/j.ceramint.2012.10.275. 
[21] J. Henry, R. Hill, The influence of lithia content on the properties of fluorphlogopite glass-ceramics. II. Microstructure hardness and machinability, J. Non-Cryst. Solids 319 (1) (2003) 13-30.

[22] L. Pauling, The Structure of the Micas and Related Minerals, Proceedings of The National Academy of Sciences. 16 (1930) 123-129. doi:10.1073/pnas.16.2.123.

[23] R. Hill, D. Wood, M. Thomas, Trimethylsilylation analysis of the silicate structure of fluoro-alumino-silicate glasses and the structural role of fluorine, J. Mater. Sci. 34 (1999) 1767-1774. doi:10.1023/A:1004550907134.

[24] D. Wood, N. Bubb, P. Bentley, S. Kilcoyne, C. Ritter, Use of kinetic neutron diffraction to observe crystallisation of a mica based glass ceramic, Glass Technology. 45 (2004) 6264(3).

[25] P.K. Maiti, A. Mallik, A. Basumajumdar, P. Guha, Influence of barium oxide on the crystallization, microstructure and mechanical properties of potassium fluorophlogopite glass-ceramics, Ceram. Int. 38 (2012) 251-258. doi:10.1016/j.ceramint.2011.06.060.

[26] A. Stamboulis, R.G. Hill, R. V. Law, S. Matsuya, MAS NMR study of the crystallisation process of apatite-mullite glass ceramics, Phys. Chem. Glas. 45 (2004) 127-133. doi:10.4028/www.scientific.net/KEM.254-256.99.

[27] D.G. Grossman. Tetrasilicic mica glass-ceramic method, US Patent, 3732087. Corning Glass Works, Corning, N.Y., 1973.

[28] G.H. Beall, Property and Process Development in Glass-Ceramic Materials, In: Glas. Curr. Issues, Springer Netherlands, Dordrecht, 1985, pp. 31-48. doi:10.1007/978-94-0095107-5 3.

[29] D.G. Grossman, Machining a machinable glass-ceramic, Vacuum, 28 (2) (1978) 55-61.

[30] Ostwald W., Blocking of Ostwald ripening allowing long-term stabilization, Phys Chem. 37 (1901) 385.

[31] P. Voorhees, The theory of Ostwald ripening, J. Stat. Phys. 38 (1985) 231-252. doi:10.1007/bf01017860.

[32] W. Höland, V. Rheinberger, M. Schweiger, K.F. Kelton, B.R. Haywood, Control of nucleation in glass ceramics, in: Philos. Trans. R. Soc. A Math. Phys. Eng. Sci., 2003: pp. 
575-589. doi:10.1098/rsta.2002.1152.

[33] P. Labarbe, A.K. Bandyopadhyay, J. Zarzycki, A. Wright, Stabilisation of crystal densities during nucleation of glass ceramics: A hidden ripening process, J. Non. Cryst. Solids. 43 (1981) 433-438. doi:10.1016/0022-3093(81)90111-3.

[34] J. Henry, X. Chen, R. V. Law, R.G. Hill, The investigation of the crystalline phases development in Macor®glass-ceramic,J.Eur.Ceram.Soc.38(2018)245-251. doi:10.1016/j.jeurceramsoc.2017.07.030.

[35] D.S. Baik, K.S. No, J.S. Chun, H.Y. Cho, Effect of the aspect ratio of mica crystals and crystallinity on the microhardness and machinability of mica glass-ceramics, J. Mater. Process. Technol. 67 (1997) 50-54. doi:10.1016/S0924-0136(96)02817-8.

[36] D.S. Baik, K.S. No, J.S. Chun, Y.J. Yoon, H.Y. Cho, A comparative evaluation method of machinability for mica-based glass-ceramics, J.Mater.Sci.30(1995)1801-1806. doi:10.1007/BF00351613.

[37] M. Taira, M. Yamaki, Studies on hardness of nine machinable ceramics for dental applications, J Mater Sci Lett. 13 (1994) 425-426. doi:10.1007/bf00278017.

[38] M. Kim, S. Oh, J. Kim, S. Ju, D. Seo, S. Jun, Wear evaluation of the human enamel opposing different Y-TZP dental ceramics and other porcelains, J. Dent. 40 (2012) 979-988. doi:10.1016/j.jdent.2012.08.004. 


\section{$\underline{\text { List of Figures }}$}

Figure 1 DSC traces of glass powder and frit for: (a) Mica I ; (b) Mica II ; (c) Mica III; (d) Mica IV.

Figure 2 XRD Results for: (a) Mica I; (b) Mica II; (c) Mica III; (d) Mica IV glassceramics after different heat treatments, showing formation of Barium fluorphlogopite [BF], Barium Aluminum Silicate[B] and Protoenstatite [E].

Figure 3 (a) SEM photomicrographs of: (a) Mica I glass-ceramic heat treated at $1150^{\circ} \mathrm{C}$ (1 hour) showing fine Mica crystals in the glass matrix; (b) Mica I glassceramic heat treated at $1200^{\circ} \mathrm{C}$ (5 hours), showing coarse Mica crystals in the glass matrix; (c) Mica I glass-ceramic heat treated at $1200^{\circ} \mathrm{C}$ ( 3 hours) showing sheets of barium fluorphlogopite crystals; (d) Cleavage along the 001 plane [interlayer site] in Mica II glass-ceramic heat treated at $1200^{\circ} \mathrm{C}(1$ hour $)$.

Figure 4 SEM micrograph showing effect of increasing barium content on (a) Mica I, (b) Mica II, (c) Mica III, and (d) Mica IV glass-ceramics heat treated at $1200^{\circ} \mathrm{C}$ for 1 hours.

Figure 5 SEM photomicrograph showing the house-of-cards microstructure in Mica III glass-ceramic heat treated at $1200^{\circ} \mathrm{C}(5$ hours $)$.

Figure 6 SEM micrograph showing fluorine deficient surface layer of the Mica I glassceramic heat treated at $1200^{\circ} \mathrm{C}(5$ hours). 


\section{List of Tables}

Table $1 \quad$ DSC and STA results of glass powder $(<45 \mu \mathrm{m})$ and frit.

Table 2

Vickers microhardness (GPa) of Mica glasses and glass-ceramics. 


\section{Figures}

Figure 1
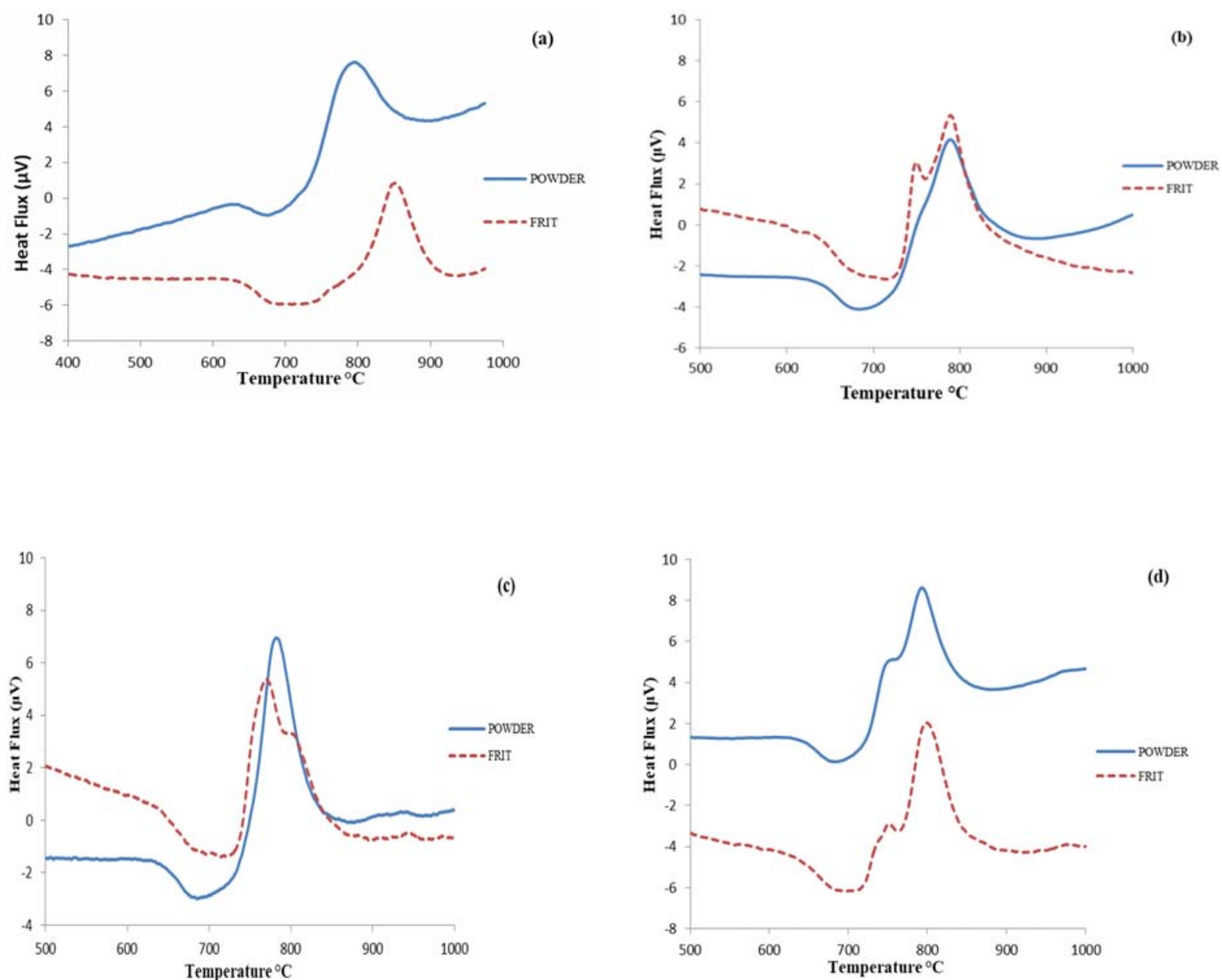

Figure 1. DSC traces of glass powder and frit for: (a) Mica I ; (b) Mica II ; (c) Mica III; (d) Mica IV. 
Figure 2
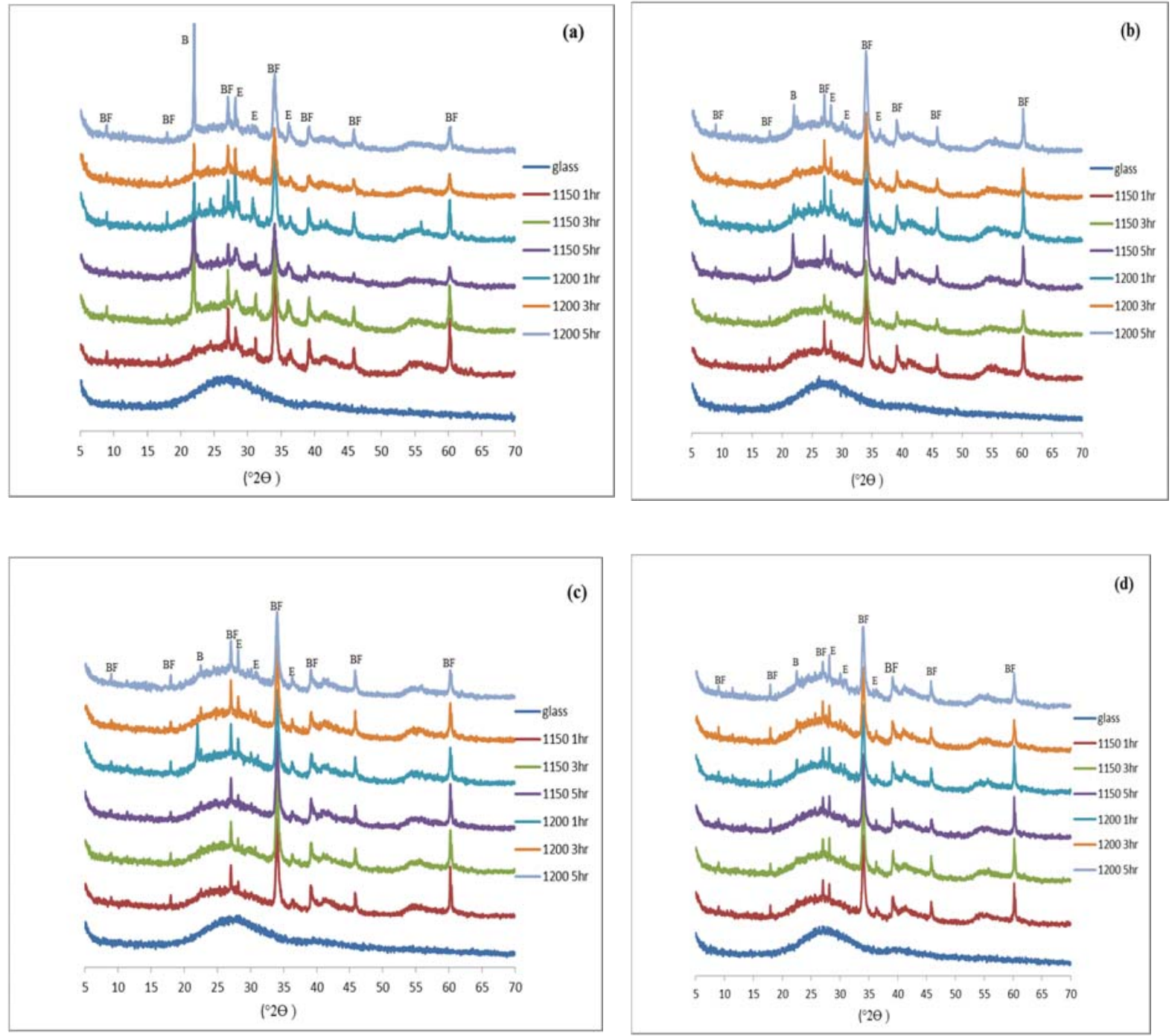

Figure 2. XRD Results for: (a) Mica I; (b) Mica II; (c) Mica III; (d) Mica IV glass-ceramics after different heat treatments, showing formation of Barium fluorphlogopite [BF], Barium Aluminum Silicate[B] and Protoenstatite [E]. 
Figure 3
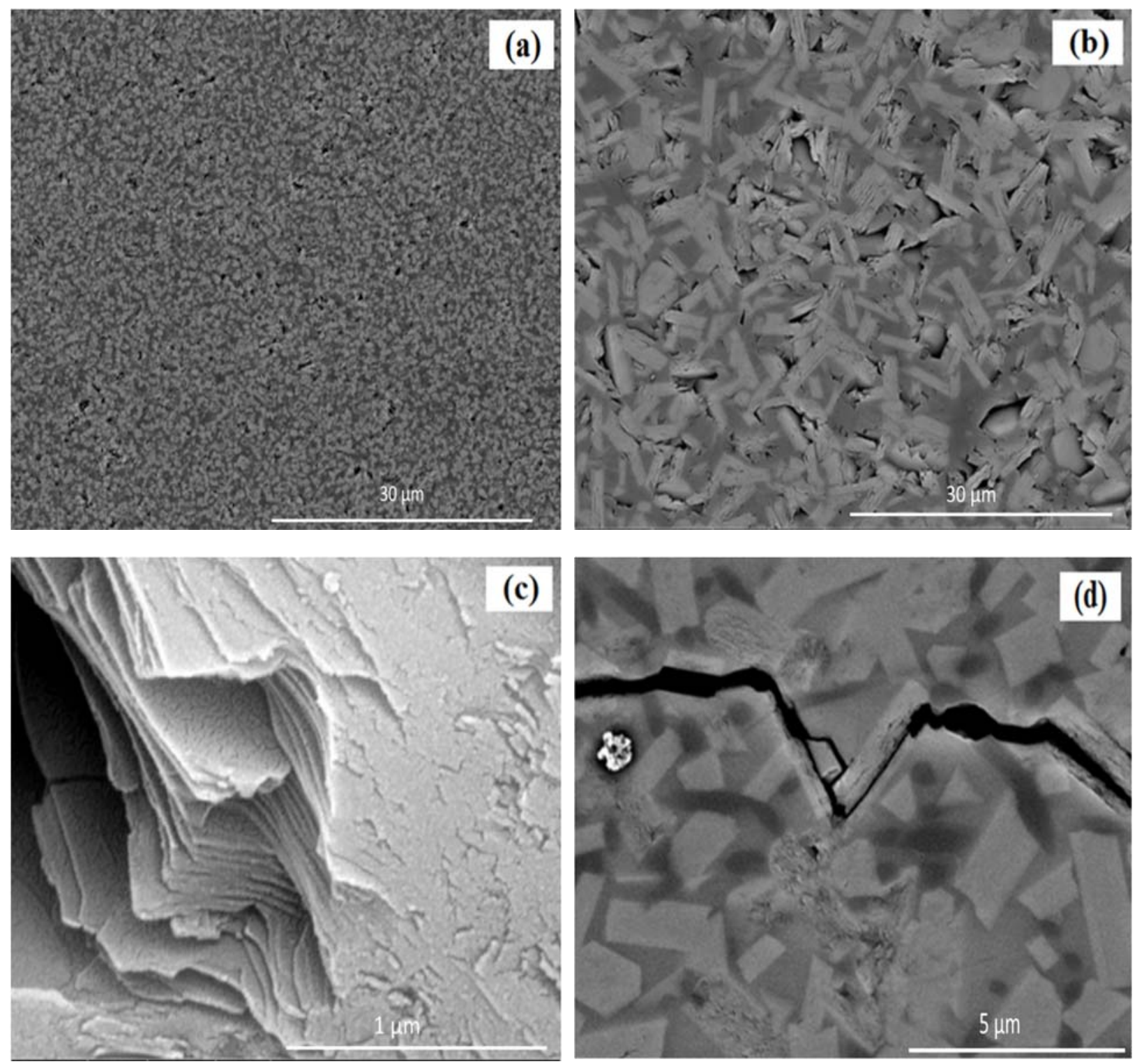

Figure 3. (a) SEM photomicrographs of: (a) Mica I glass-ceramic heat treated at $1150^{\circ} \mathrm{C}(1$ hour) showing fine Mica crystals in the glass matrix; (b) Mica I glass-ceramic heat treated at $1200^{\circ} \mathrm{C}(5$ hours), showing coarse Mica crystals in the glass matrix; (c) Mica I glassceramic heat treated at $1200^{\circ} \mathrm{C}(3$ hours) showing sheets of barium fluorphlogopite crystals; (d) Cleavage along the 001 plane [interlayer site] in Mica II glass-ceramic heat treated at $1200^{\circ} \mathrm{C}(1$ hour $)$. 
Figure 4
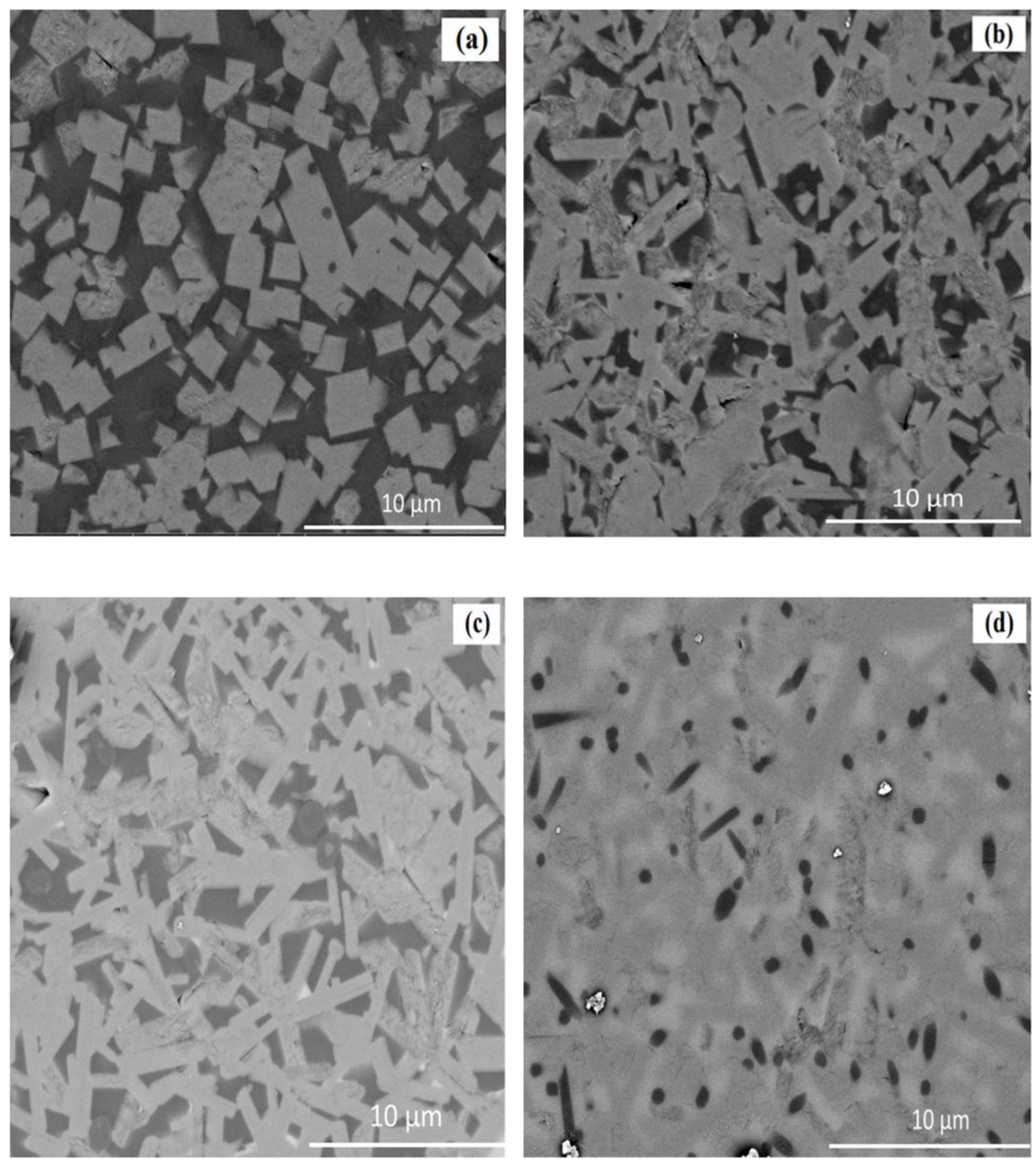

Figure 4. SEM micrograph showing effect of increasing barium content on (a) Mica I, (b) Mica II, (c) Mica III, and (d) Mica IV glass-ceramics heat treated at $1200^{\circ} \mathrm{C}$ for 1 hours. 
Figure 5

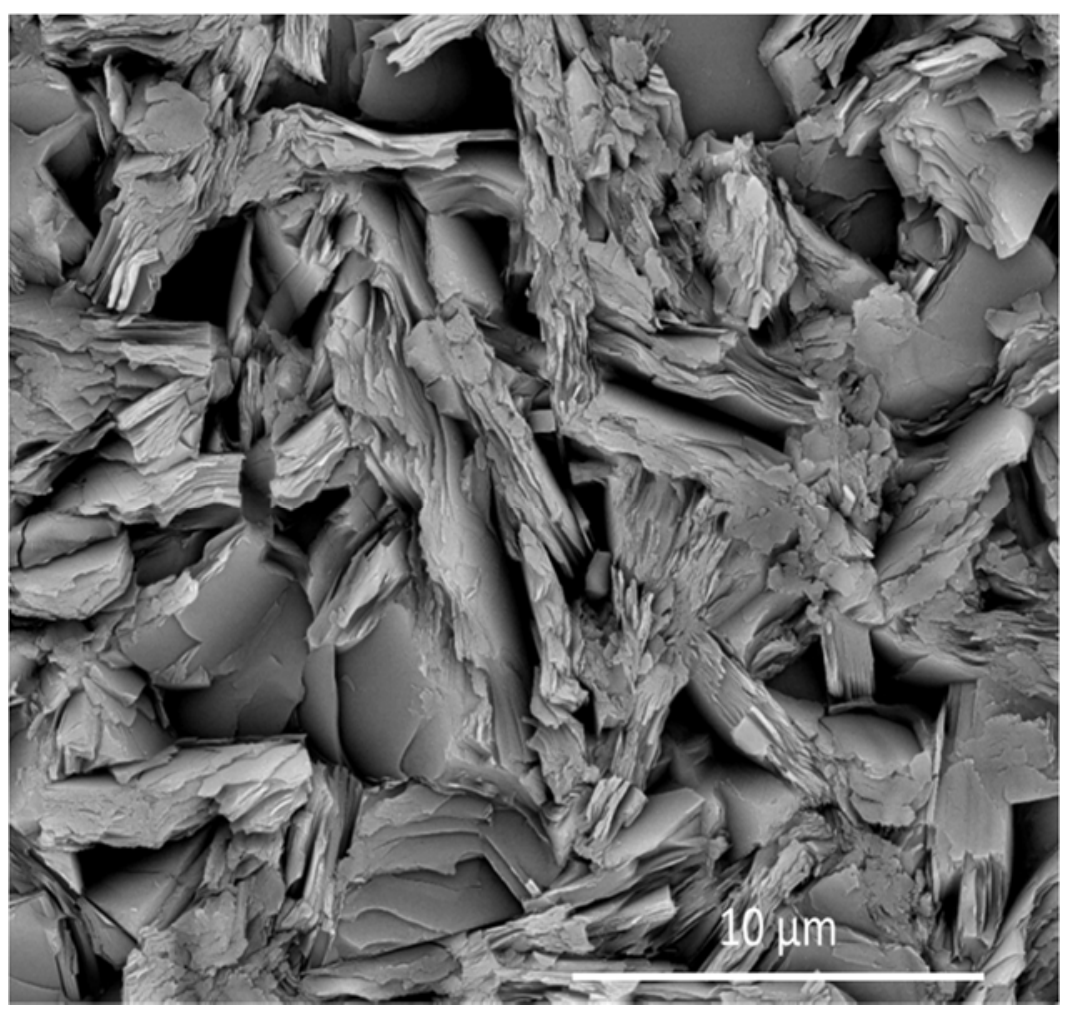

Figure 5. SEM photomicrograph showing the house-of-cards microstructure in Mica III glass-ceramic heat treated at $1200^{\circ} \mathrm{C}(5$ hours $)$. 
Figure 6

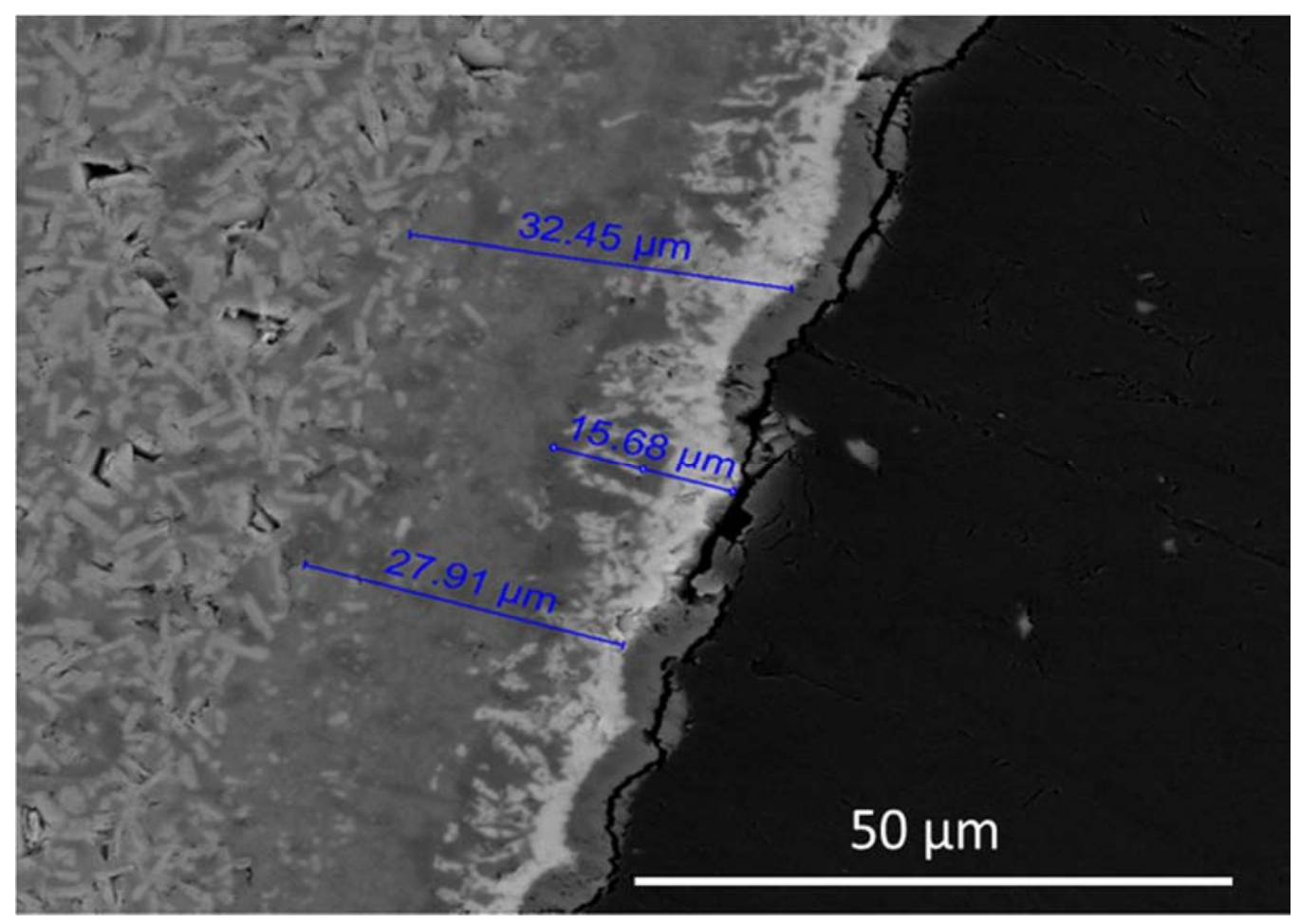

Figure 6. SEM micrograph showing fluorine deficient surface layer of the Mica I glassceramic heat treated at $1200^{\circ} \mathrm{C}(5$ hours). 
Tables

Table1. DSC and STA results of glass powder $(<45 \mu \mathrm{m})$ and frit.

\begin{tabular}{|c|c|c|c|c|c|c|c|c|}
\hline \multirow{2}{*}{ DSc $/$ STA } & \multicolumn{2}{|c|}{ Mica I glass } & \multicolumn{2}{c|}{ Mica II glass } & \multicolumn{2}{c|}{ Mica III glass } & \multicolumn{2}{c|}{ Mica IV glass } \\
\cline { 2 - 9 } & $<\mathbf{4 5} \boldsymbol{\mu \mathbf { m }}$ & $\mathbf{F r i t}$ & $<\mathbf{4 5} \boldsymbol{\mu \mathbf { m }}$ & Frit & $<\mathbf{4 5} \boldsymbol{\mu \mathbf { m }}$ & $\mathbf{F r i t}$ & $<\mathbf{4 5} \boldsymbol{\mu \mathbf { m }}$ & Frit \\
\hline $\mathbf{T}_{\mathbf{g}}\left({ }^{\circ} \mathbf{C}\right)$ & 626 & 630 & 626 & 632 & 630 & 640 & 630 & 627 \\
\hline $\mathbf{T}_{\mathbf{p}}{ }^{\mathbf{}}\left({ }^{\circ} \mathbf{C}\right)$ & 800 & 840 & 785 & 785 & 778 & 805 & 790 & 790 \\
\hline $\mathbf{T}_{\mathbf{p}}{ }^{2}\left({ }^{\circ} \mathbf{C}\right)$ & - & - & - & 748 & - & 766 & 748 & 748 \\
\hline Weight loss [\%] & 7.2 & 3.2 & 7.0 & 3.1 & 5.3 & 3.0 & 5.4 & 2.6 \\
\hline
\end{tabular}

Table 2 .Vickers microhardness (GPa) of Mica glasses and glass-ceramics.

\begin{tabular}{|c|c|c|c|c|}
\hline $\begin{array}{c}\text { Glass Heat } \\
\text { Treatment } \\
\left({ }^{\circ} \mathrm{C} / \text { Hours }\right) *\end{array}$ & $\begin{array}{c}\text { Mica I } \\
\text { Mean Micro- } \\
\text { Hardness } \\
\text { GPa (SD) }\end{array}$ & $\begin{array}{c}\text { Mica II } \\
\text { Mean Micro- } \\
\text { Hardness } \\
\text { GPa (SD) }\end{array}$ & $\begin{array}{c}\text { Mica III } \\
\text { Mean Micro- } \\
\text { Hardness } \\
\text { GPa (SD) }\end{array}$ & $\begin{array}{c}\text { Mica IV } \\
\text { Mean Micro- } \\
\text { Hardness } \\
\text { GPa (SD) }\end{array}$ \\
\hline Glass (none) & $6.7(0.3)^{\mathrm{a}}$ & $6.6(0.3)^{\mathrm{a}}$ & $6.5(0.3)^{\mathrm{a}}$ & $6.3(0.2)^{\mathrm{a}}$ \\
\hline $1150{ }^{\circ} \mathrm{C} / 1 \mathrm{~h}$ hold & $5.3(0.5)^{b}$ & $5.3(0.5)^{b}$ & $5.3(0.5)^{b}$ & $4.6(0.2)^{b}$ \\
\hline $1150{ }^{\circ} \mathrm{C} / 3$ h hold & $4.5(0.6)^{c}$ & $5.2(0.4)^{b}$ & $4.1(0.3)^{\mathrm{c}}$ & $4.6(0.4)^{b}$ \\
\hline $1150{ }^{\circ} \mathrm{C} / 5$ h hold & $4.3(0.4)^{c}$ & $5.1(0.4)^{b}$ & $3.9(0.2)^{\mathrm{c}}$ & $4.5(0.1)^{b}$ \\
\hline $1200^{\circ} \mathrm{C} / 1 \mathrm{~h}$ hold & $4.4(0.2)^{\mathrm{c}}$ & $2.9(0.3)^{\mathrm{c}}$ & $2.9(0.3)^{d}$ & $3.8(0.1)^{\mathrm{c}}$ \\
\hline $1200^{\circ} \mathrm{C} / 3 \mathrm{~h}$ hold & $3.6(0.2)^{d}$ & $3.5(0.4)^{d}$ & $1.8(0.2)^{\mathrm{e}}$ & $3.4(0.4)^{\mathrm{d}}$ \\
\hline $1200^{\circ} \mathrm{C} / 5 \mathrm{~h}$ hold & $1.3(0.1)^{\mathrm{e}}$ & $2.4(0.3)^{\mathrm{e}}$ & $1.5(0.2)^{\mathrm{f}}$ & $1.8(0.2)^{\mathrm{e}}$ \\
\hline
\end{tabular}

*All glasses received a nucleation hold for $1 \mathrm{~h}\left(660^{\circ} \mathrm{C}\right)$ prior to final heat treatment.

*Different superscript letters within groups indicates significant differences $(P<0.05)$. 